\title{
Poor social support as a risk factor for antenatal depressive symptoms among women attending public antennal clinics in Penang, Malaysia
}

\author{
Abdul Rashid ${ }^{1 *}$ and Rokiah Mohd ${ }^{2}$
}

\begin{abstract}
Background: Depression, a type of mental disorder which is portrayed by marked alterations in mood, is associated with distress and/or impaired functioning. Poor social support is an important risk factor for depression in pregnancy. An extensive literature search failed to show any published study conducted in Malaysia on antenatal depressive symptoms and the risk of poor social support on it. The aim of the study was to determine the risk of antenatal depressive symptoms due to poor social support.

Methods: This cross sectional study was conducted among 3000 pregnant women attending antenatal clinics in Penang, Malaysia. Edinburgh Postnatal Depression Scale (EPDS) was used to screen for antenatal depressive symptoms and the Oslo-3 Social Support Scale (OSS-3) was used to measure social support. Odds ratio and adjusted odds ratio were used to quantify the risk of antenatal depressive symptoms due to poor social support.

Results: The prevalence of depressive symptoms was 20\%. Using OSS-3 scale to gauge social support, most of the participants had moderate support (61.3\%) followed by poor support (22\%) and strong support (16.7\%). Social support was found to be significantly associated with depressive symptoms in this study (OR 2.2, aOR 2.1, AR 45\%).

Conclusions: Considering that an expecting mother's psychological factors are important in the wellbeing of the mother and child, antenatal depression must be quickly identified. Screening pregnant women for social support can help identify women with higher risk of depression.
\end{abstract}

Keywords: Antenatal, Depressive symptoms, Depression, Social support

\section{Plain English summary}

Pregnant women with poor social support are at higher risk for depression but despite the association with many health related events to both mother and child, antenatal depression is less studied compared to post-natal depression. An extensive literature search failed to show any published study conducted in Malaysia on antenatal depression and the risk of poor social support on it probably because like in other Asian cultures, social support is typically high in Malaysia. Pregnancy is generally considered an opportunity to expand the family lineage, so

\footnotetext{
* Correspondence: drrashid10@gmail.com

${ }^{1}$ Penang Medical College, Department of Public Health Medicine,

Georgetown, Penang, Malaysia

Full list of author information is available at the end of the article
}

expecting mothers generally receive good physical, emotional and social support from family and friends.

Malaysia is undergoing extensive rural to urban migration with most young people moving to cities for better employment opportunities. As a result of this migration, there is a transformation from extended to nuclear family household system resulting in most expecting mothers to lose the traditional social support system and inadvertently losing the proven mechanism in easing, obtaining and maintaining psychological changes and preventing depressive symptoms during pregnancy.

This study was conducted among 3000 pregnant women who attended antenatal clinics in Penang, Malaysia to determine the risk of antenatal depressive symptoms due to poor social support. One in five 
participants had depressive symptoms and poor social support was significantly associated with depressive symptoms.

\section{Background}

Depression, a type of mental disorder which is portrayed by marked alterations in mood, is associated with distress and/or impaired functioning [1]. Depression is projected to be the second leading cause of disability worldwide by 2020 and the fourth leading contributor to the global burden of disease [2]. Depression can range from mild, moderate to severe depression [3]. People with depression utilize more health care services, become a burden to caregivers, have decreased quality of life and are at risk for suicide [4].

Depression is more prevalent in women [5] and it has been reported that depression is the leading cause of disability adjusted life years for women globally [2]. Due to hormonal changes, women of child bearing age, particularly pregnant women, are at higher risk for depression [6-8]. Prevalence of antenatal depression has been reported as high as $20 \%[9,10]$. The prevalence rates reported for antenatal depression could be an underestimate considering that depressed women are less likely to participate in research due to fear, denial and stigma related to mental illness and probably because symptoms of depression could be mistaken for changes which normally occur during pregnancy, resulting in many women not seeking mental health services $[11,12]$. Despite the high prevalence and high relapse rates reported for antenatal depression, less is known concerning factors affecting antenatal depression compared to post-natal depression $[10,13,14]$.

Antenatal depression has been shown to have long lasting detrimental effect, not only on expecting mothers but also on their children and family [10, 15-17]. Although increased risks to adverse obstetrics outcome is controversial [18] some studies have shown an association of depression during pregnancy with poor attendance to antenatal clinics, intra uterine growth retardation, low birth weight, preterm delivery and failure to thrive in infants $[9,19-22]$ Women with antenatal depression are also at higher risk of preeclampsia and birth difficulties [9]. Depression during pregnancy has been linked to risk taking behaviours and unhealthy lifestyle habits including poor dietary habits leading to poor nutrition, smoking and illicit substance abuse [11, 23, 24]. Depression during pregnancy has been shown to be a predicator for postpartum depression $[9,13,25]$ and can be a risk factor for depression during subsequent pregnancy's $[22,26]$.

The risk factors for antenatal depression include genetic, environmental, psychological, biological and lack of social support $[10,27,28]$. Social support is important during the emotional and physical changes that occur in pregnancy $[25,29,30]$ and it has been shown to be an important protective factor against depression. Lack of social support is an important risk factor for depression in pregnancy $[13,23]$. Social support may be emotional or practical support which may be objective i.e. what is actually received or subjective i.e. what is perceived to have been received from partners, spouses, family members, friends, co-workers and neighbours etc. [31-33]. In this study social support is defined as the perceived support received from family members, husband/partner and friends. It is postulated that there is a correlation between perceived social support and monoamine activity in the brain [34-36].

In many Asian cultures including Malaysia, the perinatal period is valued because it is an opportunity to expand the family lineage and in general expecting mothers receive good physical, emotional and social support from family and friends [37]. However, Malaysia is undergoing extensive rural to urban migration with most young people moving to cities for better employment opportunities. As a result of this migration, there is a transformation from extended to nuclear family household system [38] resulting in most expecting mothers to lose the traditional social support system which usually comes from family members and inadvertently lose the proven mechanism in easing, obtaining and maintaining psychological changes during pregnancy and preventing depression in pregnant women [39].

Despite the association with many health related events to both the mother and child, antenatal depression is less studied compared to post-natal depression [12]. Early identification of antenatal depression provides the opportunity for the provision of best health care possible for both the mother and fetus in the primary health care setting $[12,14,40]$. Social support can be used to help identify women at higher risk of depression [30]. An extensive literature search failed to show any published study conducted in Malaysia on antenatal depressive symptoms and the risk of poor social support on it. Although research on antenatal depressive symptoms has been studied in other countries especially in the west, cultural differences may affect prevalence and associated risk factors [11, 22]. Complementing this literature with research from other contexts, such as Malaysia, is critical to ensuring the results are generalizable and reflect contextual differences. Although in general, social support is high in Malaysia especially during pregnancy but changing social structures in the country may cause a change in the social support level and may inadvertently affect depression in pregnancy. Because of these reasons the objective of this study was to determine the prevalence of antenatal depressive symptoms and the association of social support on antenatal depressive symptoms. 


\section{Methods}

\section{Study design}

This cross sectional study was conducted among expecting mothers on follow up in the Ministry of Health's antenatal clinics in Penang, Malaysia.

\section{Background place of study}

The study was conducted in Penang, one of the 14 states in Malaysia. There are five districts in Penang with approximately 30 health clinics and 60 community clinics. The health clinics are staffed by Family Medicine Specialists or by Medical officers whereas the community clinics are staffed by the staff nurses or community nurses. Due to the limitation in terms of costs and time and considering that not all community clinics and health clinics provide all levels of antenatal services, only 20 health clinics in the state which had a Family Medicine specialist on staff were used for the study.

\section{Sampling}

There were approximately 14,000 expecting mothers on antenatal follow-up in the state in 2015. All expecting mothers from the 20 selected health clinics irrespective of their gestational period and parity were included in the study. Stata was used to calculate the sample size. Using studies from Pakistan (25.0\%) and Thailand (20.5\%) [41, 42] as references, 2928 pregnant women would need to be enrolled in the study in order to determine $20 \%$ prevalence of antenatal depression with $90 \%$ power. Power of $90 \%$ was chosen to ensure higher probability of finding the estimated prevalence and because $90 \%$ power provides a sample size feasible within the study period. This study was conducted in the 20 health clinics that covered all five districts in the state. A random sampling method was used to select the participants. Every third expecting mother attending the antenatal clinics was invited to participate. Only women who could speak and understand Malay and English and provided informed consent were included in the study. Once the participant was interviewed, a colour-coded sticker was placed on the file to avoid duplication in the data collection process.

\section{Tool}

The data for this study was acquired using a questionnaire which was tested for viability and feasibility prior to the start of the study by nurses working in a maternal and health clinic. The questionnaire was adapted to incorporate feedback from this initial phase. The participants were interviewed face to face in the antenatal clinics by 10 comprehensively trained nurses using a uniform protocol which was set up to minimize error and bias. The interviews were conducted by trained nurses in private in the nurse's room to ensure privacy.
The baseline demographic information collected included age, employment status and living arrangement. Race was categorized into three major races in Malaysia which included Malay, Chinese and Indian and all other races were categorized as others. The validated Malay and English versions of the Edinburgh Postnatal Depression Scale (EPDS) were used to screen for antenatal depressive symptoms. EPDS is an effective tool to screen for postnatal as well as perinatal depressive symptoms [43]. It consists of 10 items on how the participant felt during the past week. There are four response options, scored from 0 to 3 for each item. A score of $\geq 12$ was used to define a case with depressive symptoms [44].

Social factors related to depressive symptoms assessed included participant's perception of the support she received from husband/partner and family. The Oslo-3 Social Support Scale (OSS-3) was used to measure perceived social support. OSS-3 has never been used to study association with antenatal depression although it has been used for studies on the elderly in Malaysia [45, 46]. Similar Malay version of OSS-3 used in the elderly studies in Malaysia was used in this study. OSS-3 consists of three questions stated below with possible answers:

1. How many people are you so close to that you can count on them if you have a serious personal problem - none (1), 1 to 2 (2), 3 to 5 (3) and $\geq 5$ (4)

2. How much interest and concern do people show in what you do?- a lot (5), some (4), uncertain (3), little (2) and none (1)

3. How easy is it to get practical help from neighbours if you should need it?- very easy (5), easy (4), possible (3), difficult (2) and very difficult (1)

To reflect social support, the sum score which ranged from 3 to 14, was divided into three categories; 3 to 8 'poor support', 9 to 11 'moderate support' and 12 to 14 'strong support' [47, 48]. The OSS-3 social support scale had a Cronbach's alpha coefficient of 0.67 .

\section{Analysis}

Data was tabulated, cross tabulated and analysed using SPSS version 18 and Stata SE13. Prevalence of antenatal depressive symptoms is reported along with the odds of depressive symptoms between women who reported poor perceived social support and those who reported moderate or strong perceived social support. Attributable risk for the sample and population is also reported. Poor perceived social support as measured using OSS-3, family and husbands/partner support on the pregnancy were used in the logistics regression analysis to account for confounders and results were reported as adjusted odds ratio. The data used for analysis is available as Additional file 1. 


\section{Ethics}

The research received the ethical approval form the Ministry of Health ethics committee [NMRR-12-1337-14,430]. All respondents were provided with a patient information sheet which provided information concerning the study including the reason, benefits and the participant's rights not to participate or to withdraw from the study at any time. Only after the participant had read the information sheet was she asked to give a written informed consent before starting the interview. The data is stored in the researcher's office with access to the data only available to the principal investigator. A non-identifiable code was used to ensure the confidentiality of the respondents.

\section{Results}

Out of the 3270 patients approached in the health clinics, 3000 agreed to participate and were screened using EPDS. A total of 600 (20\%) pregnant women had depressive symptoms.

Table 1 shows the demographic profile of the participants. The age of the participants ranged from 16 to 50 years old with a mean age of 29 . Most (85.7\%) of the participants were in the less than 35 years old age group. Majority were Malays (76.5\%) followed by Chinese (12.1\%), Indians (9.7\%) and of the other races $(1.7 \%)$. Most were employed full time (62.9\%) followed by those unemployed (35.5\%) and living with partners (68.8\%).

Concerning the social support variables, most of the husbands/partners in this study were very supportive $(66.6 \%)$ or supportive $(31.5 \%)$ of the pregnancy and only $2 \%$ of them were not, less or fairly supportive. Overwhelmingly the families of the participants were supportive of the pregnancy (97.4\%). Using the OSS-3 scale to gauge social support most of the participants had moderate support (61.3\%) followed by poor support (22\%) and strong support (16.7\%).

Table 2 shows the risk of depressive symptoms associated with the variables which were studied. Participants whose husbands/partners are 'not, less and fairly supportive' (OR 1.9 95\% CI 1.1;3.5) and husbands/partners who are 'supportive' (OR $1.495 \%$ CI 1.2;1.7) are at higher odds of having depressive symptoms compared to participants whose husbands/partners are 'very supportive'. Differences in age, race, religion, occupation and living arrangement were not statistically significant. Participants with poor social support, gauged using OSS-3, had about twofold higher odds of having depressive symptoms compared to participants with moderate and strong support (OR 2.1 95\% CI 1.8;2.7).

As shown in Table 3, a binary logistic regression was conducted using social support variables, the model had an overall correct predicted percentage of $80.0 \%$ and Nagelkerke $\mathrm{R}$ square 0.031 . There is a twofold
Table 1 Demographic profile and social support variables of the participants

\begin{tabular}{|c|c|c|}
\hline Variables & Frequency & Percentages \\
\hline \multicolumn{3}{|l|}{ Demographic variables } \\
\hline \multicolumn{3}{|l|}{ Age } \\
\hline$<35$ & 2570 & 85.7 \\
\hline $35-40$ & 392 & 13.1 \\
\hline$>40$ & 38 & 1.3 \\
\hline \multicolumn{3}{|l|}{ Race } \\
\hline Malay & 2294 & 76.5 \\
\hline Indian & 292 & 9.7 \\
\hline Chinese & 363 & 12.1 \\
\hline Others & 51 & 1.7 \\
\hline \multicolumn{3}{|l|}{ Occupation } \\
\hline Unemployed & 1064 & 35.5 \\
\hline Full time & 1888 & 62.9 \\
\hline Part time & 48 & 1.6 \\
\hline \multicolumn{3}{|l|}{ Living arrangement } \\
\hline Parents & 462 & 15.4 \\
\hline In laws & 447 & 14.9 \\
\hline Partner and/or children & 2064 & 68.8 \\
\hline Institution & 27 & 0.9 \\
\hline \multicolumn{3}{|l|}{ Social Support variables } \\
\hline \multicolumn{3}{|c|}{ How supportive is husband/partner on pregnancy } \\
\hline Not, less and fairly supportive & 59 & 2.0 \\
\hline Supportive & 944 & 31.5 \\
\hline Very supportive & 1997 & 66.6 \\
\hline \multicolumn{3}{|c|}{ Is the family supportive on the pregnancy } \\
\hline No & 78 & 2.6 \\
\hline Yes & 2922 & 97.4 \\
\hline \multicolumn{3}{|l|}{ OSLO } \\
\hline Poor support & 661 & 22.0 \\
\hline Moderate support & 1831 & 61.3 \\
\hline Strong support & 500 & 16.7 \\
\hline
\end{tabular}

higher odds of having depressive symptoms among those with poor social support..

\section{Discussion}

Prevalence

In the present study, $20 \%$ of the participants had depressive symptoms. In general antenatal depression has been reported to range from 10 to $20 \%$ in pregnant women $[9,10,13,26]$. In one systematic review it was found that $18.4 \%$ of pregnant women were depressed during their pregnancy and $12.7 \%$ had an episode of major depression and $14.5 \%$ had a new episode of major or minor depression during pregnancy [49]. There is a wide range in 
Table 2 Risk of depressive symptoms due to the independent variables studied

\begin{tabular}{|c|c|c|c|}
\hline Variables & $\begin{array}{l}\text { Depression } \\
\text { Symptoms } \\
\mathrm{n}(\%)\end{array}$ & $\begin{array}{l}\text { No Depressive } \\
\text { Symptoms } \\
\text { n (\%) }\end{array}$ & $\mathrm{OR}(\mathrm{Cl} \%)$ \\
\hline \multicolumn{4}{|l|}{ Demographic variables } \\
\hline \multicolumn{4}{|l|}{ Age } \\
\hline$<35$ & $523(20.4)$ & $2047(79.6)$ & Reference \\
\hline $35-40$ & 69 (17.6) & $323(82.4)$ & $0.84(0.63 ; 1.10)$ \\
\hline$>40$ & $8(21.3)$ & $30(78.9)$ & $1.04(0.48 ; 2.29)$ \\
\hline \multicolumn{4}{|l|}{ Race } \\
\hline Others & $9(17.6)$ & $42(82.4)$ & Reference \\
\hline Malay & $464(20.2)$ & $1830(79.8)$ & $1.18(0.57 ; 2.45)$ \\
\hline Indian & $67(22.9)$ & $225(77.1)$ & $1.39(0.64 ; 3.00)$ \\
\hline Chinese & $60(16.5)$ & $303(83.5)$ & $0.92(0.43 ; 1.99)$ \\
\hline \multicolumn{4}{|l|}{ Occupation } \\
\hline Part time & $9(18.8)$ & 39 (81.3) & Reference \\
\hline Unemployed & $218(20.5)$ & $846(79.5)$ & $0.96(0.79 ; 1.15)$ \\
\hline Full time & $373(19.8)$ & $1515(80.2)$ & $0.89(0.43 ; 1.88)$ \\
\hline \multicolumn{4}{|l|}{ Living arrangement } \\
\hline Parents & $94(20.3)$ & $368(79.7)$ & Reference \\
\hline In laws & $99(22.1)$ & $348(77.9)$ & $1.11(0.81 ; 1.53)$ \\
\hline $\begin{array}{l}\text { Partner and/or } \\
\text { children }\end{array}$ & $399(19.3)$ & $1665(80.7)$ & $0.94(0.73 ; 1.21)$ \\
\hline Institution & $8(29.6)$ & $19(70.4)$ & $1.65(0.70 ; 3.89)$ \\
\hline \multicolumn{4}{|l|}{ Social support variables } \\
\hline \multicolumn{4}{|c|}{ How supportive is husband/partner on pregnancy } \\
\hline Very supportive & $361(18.1)$ & $1636(81.9)$ & Reference \\
\hline Supportive & $221(23.4)$ & $723(76.6)$ & $1.39(1.15 ; 1.67)^{*}$ \\
\hline $\begin{array}{l}\text { Not, less and } \\
\text { fairly supportive }\end{array}$ & $18(30.5)$ & $41(69.5)$ & $1.99(1.13 ; 3.50)^{*}$ \\
\hline \multicolumn{4}{|c|}{ Is the family supportive on the pregnancy } \\
\hline Yes & $581(19.9)$ & $2341(80.1)$ & Reference \\
\hline No & $18(24.4)$ & $59(75.6)$ & $1.29(0.77 ; 2.19)$ \\
\hline \multicolumn{4}{|l|}{ OSLO } \\
\hline $\begin{array}{l}\text { Moderate and } \\
\text { strong support }\end{array}$ & $396(16.9)$ & $1943(83.1)$ & Reference \\
\hline Poor support & $204(30.9)$ & $457(69.1)$ & $2.19(1.79 ; 2.67)$ \\
\hline
\end{tabular}

*statistically significant

the reported prevalence of depression in pregnancy, the reported prevalence varied depending on the country, study design and stage of pregnancy studied. In the United States of America (USA) the prevalence has been reported as low as $6.9 \%$ [26] and as high as $20 \%$ [50] and in São Paolo, Brazil the prevalence was reported as $19.6 \%$ [28]. In prospective studies, 33\% of pregnant women had depressive symptoms in the USA [30] and $25 \%$ in pregnant women did in Canada [25]. The
Table 3 Social support factors as risks for Depressive symptoms

\begin{tabular}{|c|c|c|c|c|c|}
\hline Variable & B & Wald & Sig & $\mathrm{aOR}$ & $95 \% \mathrm{Cl}$ \\
\hline \multicolumn{6}{|l|}{ OSLO } \\
\hline \multicolumn{6}{|l|}{$\begin{array}{l}\text { Moderate and } \\
\text { strong support (R) }\end{array}$} \\
\hline Poor support & 0.77 & 57.758 & $<0.001$ & 2.16 & $1.77 ; 2.64$ \\
\hline \multicolumn{6}{|l|}{ Family supportive of pregnancy } \\
\hline \multicolumn{6}{|l|}{ Yes $(R)$} \\
\hline No & 0.95 & 0.12 & 0.73 & 1.10 & $0.64 ; 1.89$ \\
\hline \multicolumn{6}{|c|}{ Husband/partner supportive of pregnancy } \\
\hline $\begin{array}{l}\text { Supportive and } \\
\text { very supportive (R) }\end{array}$ & 0.32 & 1.15 & 0.28 & 1.38 & $0.77 ; 2.47$ \\
\hline Not, less and fairly supportive & & & & & \\
\hline
\end{tabular}

prevalence of depression has been reported higher among black (22\%) and immigrant women $(42 \%)$ compared to white women $(7-8.6 \%)$ [51, 52]. Studies in Turkey found the prevalence of antenatal depression at about 27\% [39, 53].In Asia the prevalence of antenatal depression has been reported higher among Pakistani women (48.4\%) and aboriginal Pakistani women (31.2\%) [52] compared to pregnant women in Hong Kong (6.4\%) [37] and in Thailand (20.5\%) [41].

The prevalence rates reported could be an underestimate because pregnant women may be less likely to participate in research and when they do they underreport their depressive symptoms [37] on purpose due to stigma, fear and denial $[11,12,54]$ or simply because they may be unaware of the services available to them [55] or they may genuinely mistake symptoms of depression with normal pregnancy [12].

\section{Social support}

In this study the risk of antenatal depressive symptoms was found to be significantly associated with poor social support. Studies have shown the importance of social support on maternal mental health [10, 26, 27, 56]. Pregnant women with poor social support are at higher risk for depression during current [13] and subsequent pregnancies [26]. Even perceived low social support can influence depressive symptoms during pregnancy [25]. Since depression during pregnancy may lead to postpartum depression [13], social support during perinatal period may have an influence on postpartum depression [22, 25, 57].

Similar to the results of the current study, a study among 896 pregnant women in Berlin found low social support as an important risk factor for depressive symptoms compared with women with medium and high social support [23]. Social support has been strongly associated with depressive symptoms in studies conducted in the USA [26, 30]. Black and Hispanic women in the USA with lower social support have higher rates of 
perinatal depressive symptoms compared to white women [29, 40, 51]. Similarly studies in Canada [58], Turkey $[39,53]$ and studies among Asians have found the association between poor social support and depression [7, 42].

Good social support protects against antenatal depression even after taking demographic variables into consideration [23, 25, 29, 59]. Psychosocial and emotional changes affect interpersonal relationships and play a role of stressors $[28,30]$ which contribute to depression. In a study to determine the temporal association between post-partum depression and intimate partner violence, found that social support was an independent protective factor for postpartum depression [60]. It has been reported that physical, verbal and sexual abuse and cultural restrictions including competing for affection while living in a joint family system may function as factors associated with depression during pregnancy in Asians $[52,61]$. Interpersonal conflicts may result in poor emotional and instrumental support from spouses, family and friends resulting in the lack of social stability and social participation [11, 23, 30, 39] leading to depressive symptoms $[23,50,56]$.

\section{Strengths and limitation}

This is the first study of its kind in Malaysia which provides important and valuable information concerning the prevalence of antenatal depressive symptoms and the influence of social support on it. However the authors are cognizant of the limitations of this study, importantly the sampling method. Sampling all expecting mothers irrespective of their gestational period and parity failed to take into consideration the variation in the hormonal and social levels, and other changes which may impact on the depressive symptoms during the different stages of pregnancy. There are many other factors which are involved in antenatal depression, shown by the Nagelkerke R square value in the regression analysis model, social support only explains a small fraction of the factors involved in the development of antenatal depressive symptoms. However understanding the role of social support is important in the Asian context which is taken for granted. The authors suggest a cohort study design involving pregnant women at different gestational ages followed through postnatally to determine the association of antenatal depressive symptoms with post-natal depression.

\section{Conclusions}

Considering that an expecting mother's psychological factors are important in the wellbeing of the mother and child [11, 15-17, 19-24, 27, 62], it is imperative that antenatal depressive symptoms are quickly identified. Poor social support can be a trigger to screen for depressive symptoms in pregnancy [12]. Screening pregnant women for social support can help identify women with higher risk of depressive symptoms [30, 63]. Because of the high cost associated with clinician interviews, some researchers have suggested using screening tools to identify depressive symptoms $[13,64])$. All pregnant women attending the maternal and child health clinics should be screened for antenatal depressive symptoms by the nursing staff using the validated translated version of the EPDS. This screening can be followed with a more structured depression scale for women screened positive for the first screen [26].

\section{Additional file}

Additional file 1: Data set for prevalance of poor social support as risk factor for antenatal depression. (SAV 28 kb)

\section{Acknowledgements}

We would like to thank the Director General of the Ministry of Heath Malaysia for his permission to publish this article and the Penang state Health department and the staff involved in helping us with the data collection. We would also like to thank Penang Medical College for the seed funding for this study.

Funding

Seed funding for the study was given by the authors institution, Penang Medical College.

\section{Availability of data and materials}

The datasets used and/or analysed during the current study are presented as additional supporting files.

\section{Authors' contributions}

$A R$ was responsible for the concept, analysis and the write up of the article and RM was responsible for the data collection and helping in writing the article. Both authors read and approved the final manuscript.

Ethics approval and consent to participate

The research received the ethical approval form the Ministry of Health ethics committee [NMRR-12-1337-14,430].

Consent for publication

Not applicable.

Competing interests

The authors declare that they have no competing interests.

\section{Publisher's Note}

Springer Nature remains neutral with regard to jurisdictional claims in published maps and institutional affiliations.

\section{Author details \\ ${ }^{1}$ Penang Medical College, Department of Public Health Medicine, Georgetown, Penang, Malaysia. ²Penang State Health Department, Penang, Malaysia.}

Received: 1 July 2017 Accepted: 27 October 2017

Published online: 02 November 2017

References

1. Satcher DS. Executive summary: a report of the surgeon general on mental health. Public Health Rep. 2000;115(1):89-101.

2. Murray CJ, Lopez AD. Global mortality, disability, and the contribution of risk factors: global burden of disease study. Lancet. 1997:349(9063):1436-42.

3. Robert CB. Depression in later life. New York: Oxford University Press; 2010. 
4. Maynard CK. Differentiate depression from dementia. Nurse Pract. 2003; 28(3):18-9. 23-17; quiz 27-19

5. Goldman LS, Nielsen NH, Champion HC. Awareness, diagnosis, and treatment of depression. J Gen Intern Med. 1999;14(9):569-80.

6. Deligiandis KM; The Psychiatry Issue Brief Committee. Depression in women during childbearing years: causes, symptoms, challenges \& treatment. Public Syst Psychosoc Adv Res Cent. 8(1). http://escholarship.umassmed.edu/cgi/ viewcontent.cgi?article $=1045 \&$ content $=$ pib.

7. Husain N, Cruickshank K, Husain M, Khan S, Tomenson B, Rahman A. Social stress and depression during pregnancy and in the postnatal period in British Pakistani mothers: a cohort study. J Affect Disord. 2012;140(3):268-76.

8. Parry BL, Newton RP. Chronobiological basis of female-specific mood disorders. Neuropsychopharmacology. 2001;25(S1):S102-8.

9. Bowen A, Muhajarine N. Prevalence of antenatal depression in women enrolled in an outreach program in Canada. J Obstet Gynecol Neonatal Nurs. 2006;35(4):491-8.

10. Leung BM, Kaplan BJ. Perinatal depression: prevalence, risks, and the nutrition link-a review of the literature. J Am Diet Assoc. 2009;109(9):1566-75.

11. Marcus SM, Heringhausen JE. Depression in childbearing women: when depression complicates pregnancy. Prim care. 2009;36(1):151-ix.

12. Misri S. Suffering in silence: the burden of perinatal depression. Can J Psychiatr. 2007;52(8):477-8.

13. Bennett HA, Einarson A, Taddio A, Koren G, Einarson TR. Prevalence of depression during pregnancy: systematic review. Obstet Gynecol. 2004; 103(4):698-709.

14. Lusskin SI, Pundiak TM, Habib SM. Perinatal depression: hiding in plain sight. Can J Psychiatr. 2007;52(8):479-88.

15. Mulder EJ. Robles de Medina PG, Huizink AC, van den Bergh BR, Buitelaar JK, Visser GH: prenatal maternal stress: effects on pregnancy and the (unborn) child. Early Hum Dev. 2002;70(1-2):3-14.

16. Paarlberg KM, Vingerhoets AJ, Passchier J, Dekker GA, Van Geijn HP. Psychosocial factors and pregnancy outcome: a review with emphasis on methodological issues. J Psychosom Res. 1995;39(5):563-95.

17. Tambyrajia RL, Mongelli M. Sociobiological variables and pregnancy outcome. Int J Gynaecol Obstet. 2000;70(1):105-12.

18. Faisal-Cury A, Araya R, Zugaib M, Menezes PR. Common mental disorders during pregnancy and adverse obstetric outcomes. J Psychosom Obstet Gynaecol. 2010;31(4):229-35.

19. Copper RL, Goldenberg RL, Das A, Elder N, Swain M, Norman G, Ramsey R, Cotroneo P, Collins BA, Johnson F, et al. The preterm prediction study: maternal stress is associated with spontaneous preterm birth at less than thirty-five weeks' gestation. National Institute of Child Health and Human Development maternal-fetal medicine units network. Am J Obstet Gynecol. 1996:175(5):1286-92.

20. Hedegaard M, Henriksen TB, Sabroe S, Secher NJ. Psychological distress in pregnancy and preterm delivery. Br Med J. 1993;307(6898):234-9.

21. Pagel MD, Smilkstein G, Regen H, Montano D. Psychosocial influences on new born outcomes: a controlled prospective study. Soc Sci Med. 1990;30(5):597-604.

22. Patel V, Rahman A, Jacob KS, Hughes M. Effect of maternal mental health on infant growth in low income countries: new evidence from South Asia. BMJ. 2004;328(7443):820-3.

23. Elsenbruch S, Benson S, Rücke M, Rose M, Dudenhausen J, PincusKnackstedt MK, Klapp BF, Arck PC. Social support during pregnancy: effects on maternal depressive symptoms, smoking and pregnancy outcome. Hum Reprod. 2006:22(3):869-77.

24. Milberger S, Biederman J, Faraone SV, Chen L, Jones J. Is maternal smoking during pregnancy a risk factor for attention deficit hyperactivity disorder in children? Am J Psychiatry. 1996;153(9):1138-42.

25. Da Costa D, Larouche J, Dritsa M, Brender W. Psychosocial correlates of prepartum and postpartum depressed mood. J Affect Disord. 2000;59(1):31-40.

26. Dietz PM, Williams SB, Callaghan WM, Bachman DJ, Whitlock EP, Hornbrook MC. Clinically identified maternal depression before, during, and after pregnancies ending in live births. Am J Psychiatry. 2007;164(10):1515-20

27. Bowen A, Muhajarine N. Antenatal depression. Can Nurse. 2006;102(9):26-30

28. Faisal-Cury A, Rossi Menezes P. Prevalence of anxiety and depression during pregnancy in a private setting sample. Arch Womens Ment Health. 2007: 10(1):25-32.

29. Jesse DE, Walcott-McQuigg J, Mariella A, Swanson MS. Risks and protective factors associated with symptoms of depression in low-income African American and Caucasian women during pregnancy. J Midwifery Womens Health. 2005;50(5):405-10.
30. Westdahl C, Milan S, Magriples U, Kershaw TS, Rising SS, Ickovics JR. Social support and social conflict as predictors of prenatal depression. Obstet Gynecol. 2007;110(1):134-40.

31. Ajrouch KJ, Blandon AY, Antonucci TC. Social networks among men and women: the effects of age and socioeconomic status. J Gerontol Ser B Psychol Sci Soc Sci. 2005;60(6):S311-7.

32. Ruth JE, Coleman P. Personality and aging: Coping and management of the self in later life. In: Birren JE, Schaie KW, Abeles RP, Gatz M, Salthouse TA, editors. The handbook of aging. Handbook of the psychology of aging. San Diego: Academic Press; 1996. p. 308-22.

33. Tomaka J, Thompson S, Palacios R. The relation of social isolation, loneliness, and social support to disease outcomes among the elderly. J Aging Health. 2006;18(3):359-84.

34. Huang HY, Lee $\mathrm{H}$, Chen KC, Lin SH, Yeh TL, Chen PS, Chiu NT, Yao WJ, Chen CC, Liao MH, et al. Serotonin transporter availability in the midbrain and perceived social support in healthy volunteers. J Psychosom Res. 2013; 75(6):577-81.

35. Martinez D, Orlowska D, Narendran R, Slifstein M, Liu F, Kumar D, Broft A, Van Heertum R, Kleber HD. Dopamine type 2/3 receptor availability in the striatum and social status in human volunteers. Biol Psychiatry. 2010;67(3):275-8.

36. Yeh TL, Lee IH, Chen PS, Yu L, Cheng SH, Yao WJ, Yang YK, Lu RB, Chiu NT. Social support and striatal dopaminergic activities: is there a connection? Prog Neuro-Psychopharmacol Biol Psychiatry. 2009;33(7):1141-6.

37. Lee DTS, Chan SSM, Sahota DS, Yip ASK, Tsui M, Chung TKH. A prevalence study of antenatal depression among Chinese women. J Affect Disord. 2004:82(1):93-9.

38. Department of Statistics, Malaysia. Population and Housing Census of Malaysia 2010. Population distribution and basic demographic chararacteristics. 2010

39. Karaçam Z, Ançel G. Depression, anxiety and influencing factors in pregnancy: a study in a Turkish population. Midwifery. 2009;25(4):344-56.

40. McKee MD, Cunningham M, Jankowski KR, Zayas L. Health-related functional status in pregnancy: relationship to depression and social support in a multi-ethnic population. Obstet Gynecol. 2001;97(6):988-93.

41. Limlomwongse N, Liabsuetrakul T. Cohort study of depressive moods in Thai women during late pregnancy and 6-8 weeks of postpartum using the Edinburgh postnatal depression scale (EPDS). Arch Womens Ment Health. 2006;9(3):131-8

42. Rahman A, labal Z, Harrington R. Life events, social support and depression in childbirth: perspectives from a rural community in the developing world. Psychol Med. 2003;33(7):1161-7.

43. Gibson J, McKenzie-McHarg K, Shakespeare J, Price J, Gray R. A systematic review of studies validating the Edinburgh postnatal depression scale in antepartum and postpartum women. Acta Psychiatr Scand. 2009;119(5):350-64.

44. Mahmud WMRW, Awang A, Mohamed MN. Revalidation of the Malay version of the Edinburgh postnatal depression scale (EPDS) among Malay postpartum women attending the Bakar Bata health Center in Alor Setar, Kedah, north west of peninsular Malaysia. Malays J Med Sci. 2003:10(2):71-5.

45. Rashid A, Manan AA, Rohana S. The influence of social support on cognitive impairment in the elderly. Australas Med J. 2016:9(8):262-9.

46. Rashid A, Tahir I. The prevalence and predictors of severe depression among the elderly in Malaysia. J Cross Cult Gerontol. 2015:30(1):69-85.

47. Brevik J, Dalgard O. The health profile inventory. Oslo: University of Oslo; 1996.

48. Dalgard OS, Dowrick C, Lehtinen V, Vazquez-Barquero JL, Casey P, Wilkinson G, Ayuso-Mateos JL, Page H, Dunn G. Negative life events, social support and gender difference in depression: a multinational community survey with data from the ODIN study. Soc Psychiatry Psychiatr Epidemiol. 2006;41(6):444-51.

49. Gavin NI, Gaynes BN, Lohr KN, Meltzer-Brody S, Gartlehner G, Swinson T. Perinatal depression: a systematic review of prevalence and incidence. Obstet Gynecol. 2005;106(5 Pt 1):1071-83.

50. Marcus SM, Flynn HA, Blow FC, Barry KL. Depressive symptoms among pregnant women screened in obstetrics settings. J Women's Health. 2003; 12(4):373-80.

51. Liu L, Setse R, Grogan R, Powe NR, Nicholson WK. The effect of depression symptoms and social support on black-white differences in health-related quality of life in early pregnancy: the health status in pregnancy (HIP) study. BMC Pregnancy Childbirth. 2013;13(1):125.

52. Shah SMA, Bowen A, Afridi I, Nowshad G, Muhajarine N. Prevalence of antenatal depression: comparison between Pakistani and Canadian women. J Pak Med Assoc. 2011;61:242-6. 
53. Golbasi Z, Kelleci M, Kisacik G, Cetin A. Prevalence and correlates of depression in pregnancy among Turkish women. Matern Child Health J. 2010;14(4):485-91.

54. Shakespeare J, Blake F, Garcia J. A qualitative study of the acceptability of routine screening of postnatal women using the Edinburgh postnatal depression scale. Br J Gen Pract. 2003;53(493):614-9.

55. Templeton L, Velleman R, Persaud A, Milner P. The experiences of postnatal depression in women from black and minority ethnic communities in Wiltshire. UK Ethn Health. 2003;8(3):207-21.

56. O'Hara MW. Social support, life events, and depression during pregnancy and the puerperium. Arch Gen Psychiatry. 1986;43(6):569-73.

57. Morikawa M, Okada T, Ando M, Aleksic B, Kunimoto S, Nakamura Y, Kubota C, Uno Y, Tamaji A, Hayakawa N, et al. Relationship between social support during pregnancy and postpartum depressive state: a prospective cohort study. Sci Rep. 2015:5:10520.

58. Zelkowitz P, Schinazi J, Katofsky L, Saucier JF, Valenzuela M, Westreich R, Dayan J. Factors associated with depression in pregnant immigrant women. Transcult Psychiatry. 2004;41(4):445-64.

59. Hueston WJ, Kasik-Miller S. Changes in functional health status during normal pregnancy. J Fam Pract. 1998;47(3):209-12.

60. Faisal-Cury A, Menezes PR, d'Oliveira AF, Schraiber LB, Lopes CS. Temporal relationship between intimate partner violence and postpartum depression in a sample of low income women. Matern Child Health J. 2013;17(7):1297-303.

61. Kazi A, Fatmi Z, Hatcher J, Kadir MM, Niaz U, Wasserman GA. Social environment and depression among pregnant women in urban areas of Pakistan: importance of social relations. Soc Sci Med. 2006;63(6):1466-76.

62. Andersson L, Sundstrom-Poromaa I, Wulff M, Astrom M, Bixo M. Implications of antenatal depression and anxiety for obstetric outcome. Obstet Gynecol. 2004;104(3):467-76.

63. Righetti-Veltema M, Conne-Perreard E, Bousquet A, Manzano J. Risk factors and predictive signs of postpartum depression. J Affect Disord. 1998:49(3):167-80.

64. Siu AL, Bibbins-Domingo K, Grossman DC, Baumann LC, Davidson KW Ebell M, Garcia FA, Gillman M, Herzstein J, Kemper AR, et al. Screening for depression in adults: US preventive services task force recommendation statement. JAMA. 2016:315(4):380-7.

\section{Submit your next manuscript to BioMed Central and we will help you at every step:}

- We accept pre-submission inquiries

- Our selector tool helps you to find the most relevant journal

- We provide round the clock customer support

- Convenient online submission

- Thorough peer review

- Inclusion in PubMed and all major indexing services

- Maximum visibility for your research

Submit your manuscript at www.biomedcentral.com/submit 